\title{
Monitoring of Respiratory Infections in the Intensive Area of Respiratory System Disease
}

\author{
Filippo Ricciardiello ${ }^{*}$, Maria Cardone ${ }^{2}$, Giuseppe Fiorentino ${ }^{3}$, Massimo Mesolella ${ }^{1}$, \\ Flavia Oliva1, Annalisa Pianese1, Carlo Antonio Leone ${ }^{4}$ \\ ${ }^{1}$ UOC of Otorhinolaryngology, "Federico II" University, Naples, Italy \\ ${ }^{2}$ UOC Subintensive Respiratory Therapy Unit, "Monaldi" Hospital, Naples, Italy \\ ${ }^{3}$ UOC Respiratory Diseases, Physiopathology and Rehabilitation, Second University of Naples, "Monaldi" \\ Hospital, Naples, Italy \\ ${ }^{4}$ UOC of Otorhinolaryngology, "Monaldi" Hospital, Naples, Italy \\ Email: ${ }^{\text {filipporicciardiello@virgilio.it }}$
}

Received 24 May 2014; revised 17 June 2014; accepted 17 July 2014

Copyright (C) 2014 by authors and Scientific Research Publishing Inc.

This work is licensed under the Creative Commons Attribution International License (CC BY).

http://creativecommons.org/licenses/by/4.0/

(c) (i) Open Access

\section{Abstract}

Respiratory infections are the most frequent nosocomial infections after those urinaries and surgicals. We analysed respiratory infection incidences in patients treated with different kinds of respiratory assistance (non-invasive ventilation and invasive mechanical ventilation trough tracheostomy), studying 640 patients recovering in the intensive area of respiratory disease from 2010 to 2013 . We had 113 cases of respiratory infections: $42.5 \%$ in patients of non-invasive ventilation group and $57.5 \%$ of patients treated with invasive ventilation with a statistically significant difference between the two groups. The patients treated with non-invasive ventilation showed a lower incidence of nosocomial respiratory infections. Prevention guidelines are important to reduce nosocomial infections frequency.

\section{Keywords}

Intensive Respiratory Area, Multi-Resistant Pathogens, Nosocomial Infections, Pneumonias, Tracheostomy

\section{Introduction}

The lower respiratory tract infections (LTRI) can be divided into two groups: community pneumonias and no-

"Corresponding author.

How to cite this paper: Ricciardiello, F., Cardone, M., Fiorentino, G., Mesolella, M., Oliva, F., Pianese, A. and Leone, C.A. (2014) Monitoring of Respiratory Infections in the Intensive Area of Respiratory System Disease. Advances in Microbiology, 4, 560-566. http://dx.doi.org/10.4236/aim.2014.49062 
socomial pneumonias. The first can be again divided into community acquired pneumonias (CAP) and acute exacerbation of chronic bronchitis (AECOPD); the latter can be divided into hospital-acquired pneumonias (HAP), ventilator-associated pneumonias (VAP) and healthcare-associated pneumonias (HCAP).

Hospital acquired pneumonias (HAP) can be defined as pneumonias contracted during the hospital stay; they appear 48 - 72 hours after admission or discharge from another hospital.

Ventilator-associated pneumonias (VAP) can occur during mechanical ventilation, 48 - 72 hours after endotracheal intubation. Healthcare-associated pneumonias (HCAP) arise in patients hospitalised for at least two days, in three months before the infection, or in patients residing in rest homes or long-term care units, or in patients receiving antibiotic infusion therapy at home, or in patients with medicated wound or dialysis within 30 days before the infection [1].

The incidence of nosocomial pneumonias is the third highest among all nosocomial diseases (17.3\%), after urinary tract infections (27.2\%), surgery infections (18.7\%) and ahead of septicemia (15.8\%). Pneumonias occur in $27 \%-40 \%$ of patients assisted with invasive mechanical ventilation and in $20 \%-25 \%$ of patients hospitalised in the intensive area.

In $33 \%-50 \%$ of patients assisted in a hospital ward, death is more frequently due to infections caused by Acinetobacter spp., Pseudomonas aeruginosa, Stenotrophomonas maltophilas because of antibiotic therapy ineffective or concurrent medical conditions. Factors affecting mortality in these patients are the virulence of the pathogens that cause changes in the structure of the lung parenchyma that leads to deficiency of lung function [2], the severity of the conditions that caused the hospitalisation and concomitant diseases [3] [4], inadequate or delayed antibiotic therapy [5] (Table 1). The last is the only modifiable element.

Nosocomial pneumonia arising involves an increase of hospitalisation days (average 7 - 9 days), necessary to diagnosis and therapy.

Regarding as the CAP, the most frequent etiological agents implicated are Streptococcus pnuemoniae (20\% $60 \%)$, Haemophilus influenzae (3\% - 10\%), Mycoplasma pneumoniae (5\% - 50\%), Clamydia pneumoniae (5\% 15\%), Moraxella catarralis (1\% - 3\%), Staphilococcus aureus meticillin-sensible/resistant (MS/MR) and gram-negative bacilli like Pseudomonas aeruginosa (2\% - 10\%); indeed for the AECOPD Streptococcus pnuemoniae (20\% - 30\%), Haemophilus influenzae (40\% - 50\%), Moraxella catarrhalis (5\% - 10\%) are the most important agents implicated.

About the HCAP, the most involved agents are Staphilococcus aureus (29\% - 33\%), enteric gram-negative germs (15\% - 24\%), Pseudomonas aeruginosa (4\% - 14\%), while for the VAP Pseudomonas aeruginosa, Staphilococcus aureus and Acinetobacter baumanii.

The frequency of multi-resistant pathogens is significantly increased, especially in patients admitted in intensive units.

\section{Table 1. Risk factors for HAP/VAP.}

\begin{tabular}{|c|c|c|c|}
\hline Co-Morbid Illnesses & ICU Therapies & Injuries & Ventilation \\
\hline Cancer & CPR & Burns & $\begin{array}{c}\text { Duration of mechanical } \\
\text { ventilation }\end{array}$ \\
\hline $\begin{array}{c}\text { Chronic obstructive } \\
\text { pulmonary disease (COPD) }\end{array}$ & Corticosteroid use & Coma & $\begin{array}{c}\text { Intracuff pressure }<20 \mathrm{~cm} \\
\mathrm{H}_{2} \mathrm{O}\end{array}$ \\
\hline Chronic cardiac disease & Generale surgery & Head injury & Reintubation \\
\hline \multirow[t]{7}{*}{ Kidney failure } & Neurosurgery & $\begin{array}{l}\text { Multiple organ system failure } \\
\text { (MOSF) }\end{array}$ & \\
\hline & Antacid & $\begin{array}{c}\text { Acute respiratory } \\
\text { distress sindrome (ARDS) }\end{array}$ & \\
\hline & Paralytic agents & & \\
\hline & Prior antibiotic therapy & & \\
\hline & Tracheostomy & & \\
\hline & Use of nasogastric tube & & \\
\hline & $\begin{array}{l}\text { Large volume gastric } \\
\text { aspiration }\end{array}$ & & \\
\hline
\end{tabular}


This multi-resistance seems to be due to structural characteristics constitutive of the pathogen (low membrane permeability and efflux pumps on the membrane), acquired characteristics (mutation and acquisition of genetic material) and ability of the micro-organism to survive in humans.

Risk factors for the multi-resistance onset are:

- antibiotic treatment in the 90 days preceding;

- recent hospitalisation ( $>5$ days);

- high prevalence of antibiotic resistance in the territory or in hospitals;

- presence of HCAP risk factors (hospitalisation for at least 2 days in the 3 months before the onset of pneumonia; residence in a nursing home or a long-term care facility; infusion therapy; antibiotic or chemotherapy at home; dressing to wound care; onset of lung infection within 30 days after dialysis of relatives of MDR);

- diseases and/or immunosuppressive drugs [1].

A HAP arises when the delicate balance between host defences and the microbial propensity to colonisation and invasion slides in favor of the ability of pathogens to colonise and to invade the lower respiratory tract, after overcoming host defenses, which may be:

- mechanical (mucociliary clearance);

- humoral (antibody and complement);

- cellular (macrophages, polymorphonuclears, lymphocytes and their mediators).

The sources of microorganisms that cause HAP and VAP can be endogenous (oropharynx, nasal flow, trachea, sinusitis, gastric juices) or exogenous (environment, nebulizers, ventilators circuits, catheters, bronchoscopy, healthcare professionals and the patients themselves). The endogenous agents penetrate into the lower respiratory tract after aspiration by the patient; the exogenous agents penetrate through inhalation from ambient air.

The risk conditions that may favor the onset of pneumonia are:

- "patient-related" (advanced age, chronic lung disease, cancer, cerebrovascular disease, diabetes, prolonged hospitalisation, malnutrition);

- "acquired by the patient" during his stay in hospital as a result of invasive procedures-intubation, fibrobroncosopia, esophagogastroduodenoscopy, enteral nutrition—or surgery, or by taking medication (steroids, antibiotics, sedatives);

- "pathogen-related" (pyrogenic toxins, destruction ciliary, mucous adhesion) [6].

The aim of this study is to show that nosocomial respiratory infections have different frequencies in patients treated with invasive mechanical ventilation (IMV) with a tracheostomy and in patients with non-invasive ventilation $\left(\mathrm{NIV} / \mathrm{O}_{2}\right)$.

\section{Methods}

This retrospective observational study was conducted on 640 patients hospitalised in the Department of Respiratory Diseases of "Monaldi” Hospital of Naples from 2010 to 2013 (Table 2).

The 30\% of patients (192 patients) were treated with invasive mechanical ventilation trough a tracheostomy (5\% of these had undergone a surgical tracheostomy) and 70\% (448 patients) were in non-invasive ventilation (41\% NIV-29\% with $\mathrm{O}_{2}$ ).

They were subjected to X-ray examinations (chest X-ray and computed tomography), hemogasanalysis (HGA) in ambient air and after 2 hours of ventilator treatment.

Some collections of samples from the airways (spontaneous sputum, bronchial aspirate and trachea-aspirate) were used for microbiological tests in the first 24 hours of hospitalization and after 7 and 14 days and at discharge.

Table 2. Patients characteristics.

\begin{tabular}{cccc}
\hline Characteristics & O2 & NIV/CPAP & Trachea \\
\hline Patients no. & 186 & 262 & 192 \\
Age (years) & $65 \pm 6$ & $68 \pm 8$ & $71 \pm 6$ \\
Gender & $52 \mathrm{~F} 134 \mathrm{M}$ & $67 \mathrm{~F} 195 \mathrm{M}$ & $49 \mathrm{~F} 143 \mathrm{M}$ \\
Diabetes \% & 10 & 12 & 9 \\
Cardiopathy \% & 25 & 27 & 35 \\
\hline
\end{tabular}


The patients were subjected to empirical antibiotic therapy according to the guidelines (ATS/IDSA 2005) [1], with subsequent modification based on antibiogram.

For statistical analysis patients were divided into two groups: the first included patients treated with $\mathrm{O}_{2}$-therapy and with non-invasive ventilation (called " $\mathrm{O}_{2} / \mathrm{NIV}$ ”), the second included patients treated with invasive mechanical ventilation trough a tracheostomy (called "IMV").

The results were compared using a $\chi^{2}$ test.

Since 2007 we have introduced preventive measures against nosocomial infections, then approved by the Hospital Infection Control Committee [7].

One month after discharge, patients had undergone to chest X-ray, HGA, blood exams, microbiological exam on sputum/tracheal aspirate (and cannula change for patients with tracheostomy). Follow-up was stopped after three negative microbiological exams (once a month).

\section{Results}

Nosocomial respiratory infections were represented by pneumonias and tracheo-bronchitis. We observed 113 cases of respiratory infections, 61 tracheo-bronchitis and 52 pneumonias.

The frequency of these infections was different for each group: 48 cases (42.5\%) of patients in NIV group (included 19 patients treated with $\mathrm{O} 2$ and 29 patients treated with non-invasive ventilation NIV) and 65 cases (57.5\%) of patients treated with invasive ventilation trough a tracheostomy (Figure 1).

The frequency difference between the two groups resulted statistically significant $\left(\chi^{2}=49.5 ; \alpha=0.05 ; \mathrm{p}=\right.$ $0.0000)$.

The most common pathogens isolated were Acinetobacter baumani (34\%), Pseudomonas aeruginosa (22\%), Staphylococcus aureus meticillin-resistant (17\%), enterobacteriaceae estended spectrum $\beta$-lactamases producing (21\%), Haemophilus influenzae (2\%), Moraxella catarrhalis (2\%), Streptococcus pneumoniae (2\%) (Figure 2, Figure 3).

All patients with respiratory infections were first treated with an empirical antibiotic therapy (monotherapy or association therapy if it was possible the presence of MDR germs), based on guidelines [1].

Discharges duration was medially twenty days. Follow-up were stopped after three consecutive microbiological exams negative (one/month).

After a three years follow-up we had: $40 \%$ of patients colonized (all patients with a tracheostomy), 35\% normal and 25\% died.

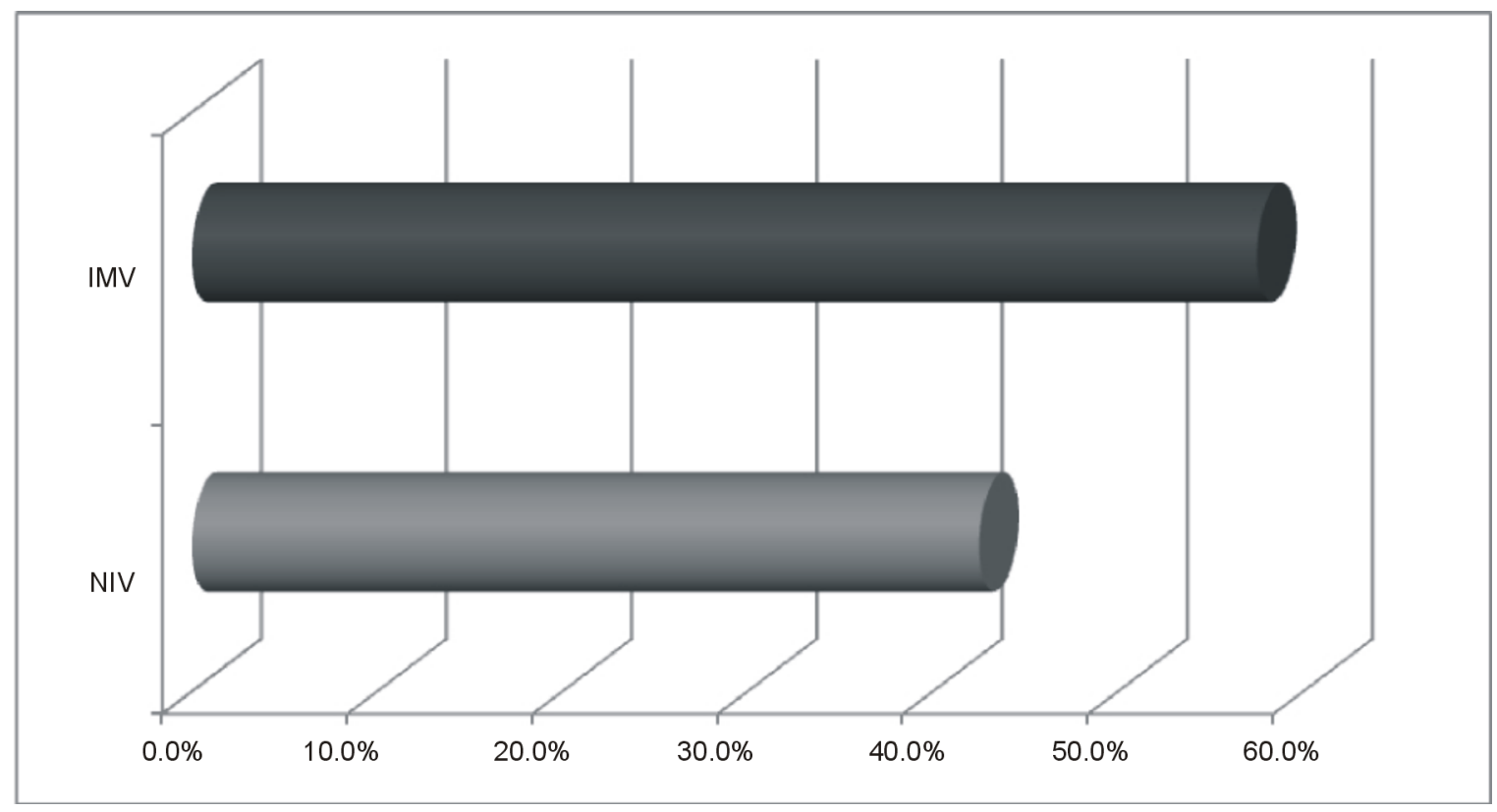

Figure 1. Respiratory infections frequency in patients with and without tracheostomy. The difference between these two groups is statistically significant $\left(\chi^{2}=49.5 ; \alpha=0.05 ; \mathrm{p}=0.0000\right)$. 


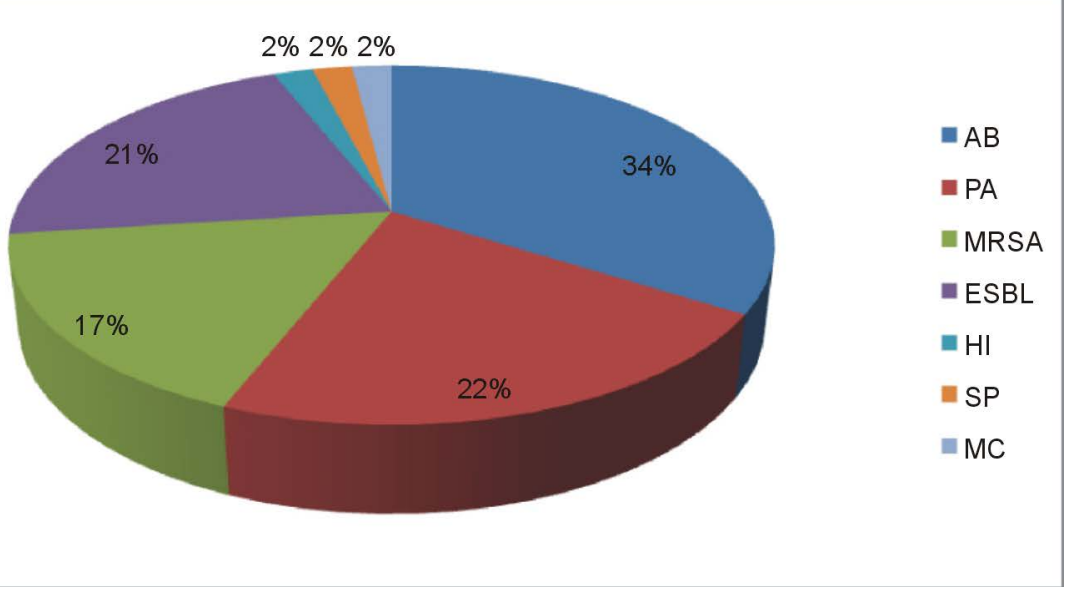

Figure 2. Microbiological agents frequency. Acinetobacter baumani (AB), Pseudomonas aeruginosa (PA), Staphylococcus aureus meticillin-resistant (MRSA), Enterobacteriaceae estended spectrum $\beta$-lactamases producing (ESBL), Haemophilus influenzae (HI), Moraxella catarrhalis (MC), Streptococcus pneumoniae (SP).

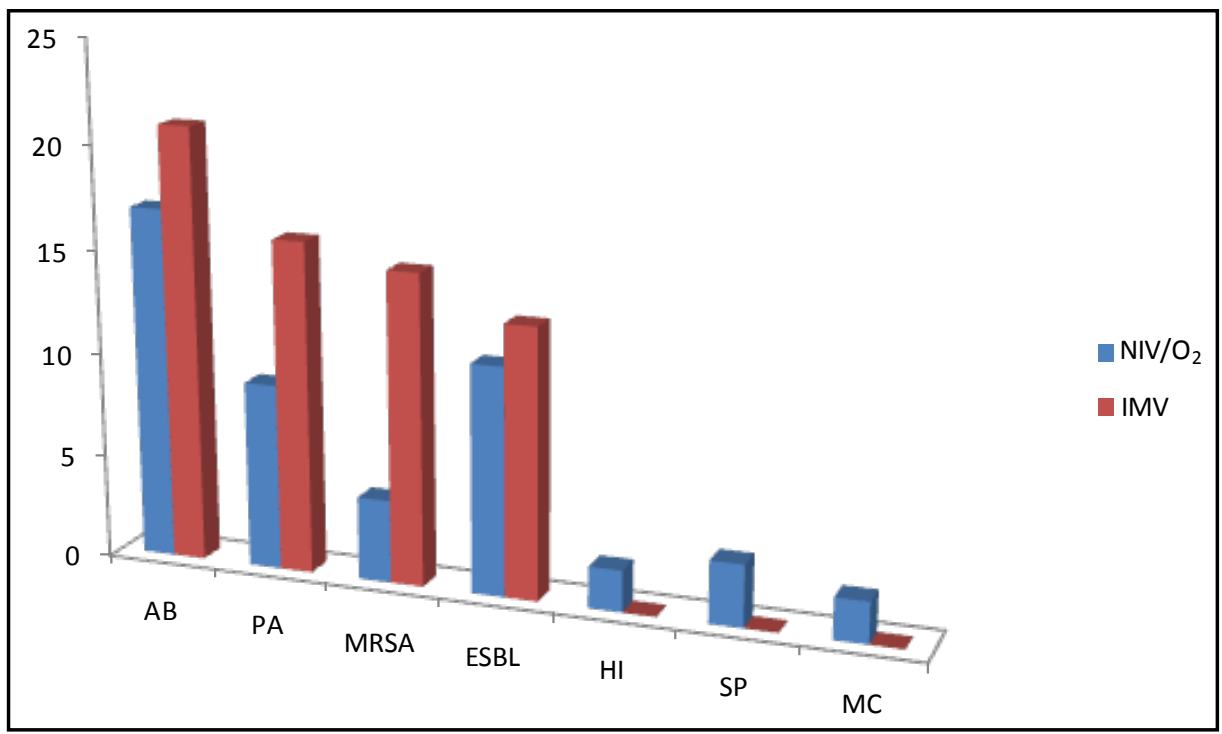

Figure 3. Frequency of nosocomial pneumonias germs in patients with or without trachestomy (Y axis: number of cases; $\mathrm{X}$ axis: etiological agents); Acinetobacter baumani (AB), Pseudomonas aeruginosa (PA), Staphylococcus aureus meticillin-resistant (MRSA), Enterobacteriaceae estended spectrum $\beta$-lactamases producing (ESBL), Haemophilus influenzae (HI), Moraxella catarrhalis (MC), Streptococcus pneumoniae (SP).

\section{Discussion}

In our study we showed the different incidences of respiratory nosocomial infections in patients of intensive respiratory area in our hospital, treated with $\mathrm{O}_{2}$-therapy/non-invasive ventilation and patients treated with invasive mechanical ventilation trough a tracheostomy. The difference between these two groups was statistically significant and respiratory infections resulted more frequent in patients with a tracheostomy.

NIV is associated with a lower incidence of nosocomial respiratory infections because it does not damage the airways and does not reduce lung defence, contrary to intubation and mechanical ventilation [8]. In particular, NIV reduces the incidence of infections in patients with COPD acute exacerbation [9], even if we observed airways colonisation by Gram-negative bacilli in NIV treatment of patients with severe COPD exacerbation.

To reduce the infections frequency, we have studied control measures and monitored their progress in the 
structure under consideration; we have also followed prevention protocols, approved by Hospital Infection Control Committee [7].

Patients stay in a single or in a cohort room (distance between patients beds $=1.5 \mathrm{~m}$ ) and they have a private bathroom. Staff and guests have to pay particular attention to hand washing, use of gloves, masks and gowns. In fact, the sources of infection could be environmental (air, water, food and surfaces, other patients and health professionals), equipment (endotracheal tube, suction catheters, bronchoscopes, fans and nasogastric tubes) [10]-[13].

The pathogens penetrate into the lower respiratory tract, colonise it, overcome host defences (mechanical, humoral and cellular) and generate the infection. The conditions predisposing to the onset of such infections may be patient-related, acquired by the patient or pathogen-related. We can act on the acquired patient conditions such as diagnostic procedures and antibiotic therapy.

With a good HAP/VAP/HCAP management, we found that it is important to achieve some objectives:

- early lung infection diagnosis;

- collection of an appropriate culture;

- a timely and appropriate empiric therapy;

- antimicrobial drugs decrease, if it is possible;

- identification of extrapulmonary infection.

To achieve these goals it is not only sufficient for a clinical approach, but to reserve microbiological strategy to intubated patients [1].

Each patient was subjected to chest X-ray and/or CT scan; we took samples from the airways for microbiological tests in the first 24 hours of hospitalisation and after 7 and 14 days. In case of probable infection, an early empirical antibiotic therapy was started before having microbiological tests results.

The most accurate way to start an empirical antibiotic therapy is to follow "clinical criteria", defined by the radiographic presence of lung infiltrates of infectious origin, or recent progression, associated with at least two of the three clinical parameters (fever, purulent secretions, leukocytosis or leukopenia) [1].

The valuation of a unique clinical parameter, high-sensitive but low-specific, caused an increased antibiotics use; however, valuating all three clinical parameters could be dangerous because of low-sensitivity, and patients with pneumonia could not be treated.

Microbiological criteria and pathogen identifications are also important for the right therapy in patients with HAP, but waiting microbiological tests, without giving an empirical therapy to the patients, could delay the therapy beginning and so increase the patients' mortality.

For ventilated patients chest X-rays are important, even if the accuracy of the portable X-ray equipment is not reliable, to evaluate the severity of their condition, an hemogasanalysis (that check presence of respiratory or metabolic acidosis/alcalosis) and complete blood counts (that shows organ dysfunction) [14].

The guidelines ATS/IDSA 2005 proposed empiric therapy “timely” [15], without waiting for microbiological results [16].

The initial choice of antibiotics must always be guided by careful assessment on the presence or absence of risk factors for specific pathogens and early or late infection and the knowledge of the patterns of resistance at local level.

Once a clinical diagnosis of nosocomial pneumonia has been done, a sample of tracheobronchial secretions is taken to perform the microbiological examination and afterwards to start a specific antibiotic therapy.

If there is a risk of the presence of MDR pathogens, it should be useful for a broad-spectrum antibiotic therapy with combination of several antibiotics, but if there is not this risk, a targeted monotherapy is sufficient [1].

If after 48 - 72 hours, there is an improvement of the clinical condition and if the culture is negative, it is possible discontinue antibiotic therapy [17]; instead if the test is positive, it is necessary continue the therapy, deescalating antibiotics dose in 7 - 8 days with following reevaluation.

If there are no clinical improvements and culture tests are negative, it is right to look for another infection site, other pathogens, complications or concomitant disease presence; instead, if culture testa are positive, it is necessary to modify the therapy based on antibiogram.

Multi-resistant pathogens should always be considered to obtain a favourable prognosis before designing an empirical regimen, especially in patients with risk factors for MDR [1]. Elderly residents of nursing homes with suspected pneumonia (HCAP) should also receive appropriate therapy for MDR pathogens. 


\section{Conclusions}

The use of invasive mechanical ventilation should be avoided, where possible, and non-invasive ventilation should be preferred, because NIV is associated with a lower incidence of nosocomial respiratory infections.

We have studied control measures and we have monitored their progress in our structure to reduce infection frequencies; we have also followed prevention protocols, approved by Hospital Infection Control Committee.

For a good HAP/VAP/HCAP management, an early diagnosis and a right "empiric" therapy, also considering possibility of MDR pathogens, are important; then therapy should be based on culture results.

\section{References}

[1] ATS/IDSA (2005) Guidelines for the Management of Adults with Hospital-Acquired, Ventilator-Associated and Healthcare-Associated Pneumonia. AJRCCM, 171, 388-416.

[2] Rello, J., Jubert, P., Vallés, J., Artigas, A., Rue, M. and Niederman, M.S. (1996) Evaluation of Outcome for Intubated Patients with Pneumonia Due to Pseudomonas aeruginosa. Clinical Infectious Diseases, 23, 973-978. http://dx.doi.org/10.1093/clinids/23.5.973

[3] Rello, J., Rue, M., Jubert, P., Muses, G., Sonora, R., Valles, J. and Niederman, M.S. (1197) Survival in Patients with Nosocomial Pnuemonia: Impact of the Severity of Illness and the Etiologic Agent. Critical Care Medicine, 25, 18621867. http://dx.doi.org/10.1097/00003246-199711000-00026

[4] Rello, J., Ollendorf, D.A., Oster, G., Vera-Llonch, M., Bellm, L., Redman, R. and Kollef, M.H. (2002) Epidemiology and Outcomes of Ventilator-Associated Pneumonia in A large US Database. Chest, 122, 2115-2121. http://dx.doi.org/10.1378/chest.122.6.2115

[5] Yates, R.R. (1999) New Intervention Strategies for Reducing Antibiotic Resistance. Chest, 115, 24S-27S. http://dx.doi.org/10.1378/chest.115.suppl_1.24S

[6] Georges, H., et al. (2000) Predisposing Factors for Nosocomial Pneumonia in Patients Receiving Mechanical Ventilation and Requiring Tracheotomy. Chest, 118, 767-774. http://dx.doi.org/10.1378/chest.118.3.767

[7] Crivaro, V., Pagano, L., Rispo, A., Sagliocco, G. and Utili, R. (2007) Gestione del Paziente Colonizzato o con Infezione da Germi Sentinella. AORN V, Monaldi.

[8] Girou, E., Brun-Buisson, C., Taille, S., Lemaire, F. and Brochard, L. (2003) Secular Trends in Nosocomial Infections and Mortality Associated with Noninvasive Ventilation in Patients with Exacerbation of COPD and Pulmonary Edema. JAMA, 290, 2985-2991. http://dx.doi.org/10.1001/jama.290.22.2985

[9] Ferrer, M., Ioanas, M., Arancibia, F., Marco, M.A., De la Bellacasa, J.P. and Torres, A. (2005) Microbial Airway Colonization Is Associated with Noninvasive Ventilation Failure in Exacerbation of Chronic Obstructive Pulmonary Disease. Critical Care Medicine, 33, 2003-209. http://dx.doi.org/10.1097/01.CCM.0000178185.50422.DB

[10] Chastre, J. and Fagon, J.Y. (2002) Ventilator-Associated Pneumonia. American Journal of Respiratory and Critical Care Medicine, 165, 867-903. http://dx.doi.org/10.1164/ajrccm.165.7.2105078

[11] Craven, D.E. and Steger, K.A. (1995) Epidemiology of Nosocomial Pneumonia. Chest, 108, 1S-16S. http://dx.doi.org/10.1378/chest.108.2_Supplement.1S

[12] Torres, A., Aznar, R., Gatell, J.M., Jiménez, P., González, J., Ferrer, A., Celis, R. and Rodriguez-Roisin, R. (1990) Incidence, Risk, and Prognosis Factors of Nosocomial Pneumonia in Mechanically Ventilated Patients. American Review of Respiratory Disease, 142, 523-528. http://dx.doi.org/10.1164/ajrccm/142.3.523

[13] Kollef, M.H. (1999) The Prevention of Ventilator-Associated Pneumonia. NEJM, 340, 627-634. http://dx.doi.org/10.1056/NEJM199902253400807

[14] Delclaux, C., Roupie, E., Blot, F., Brochard, L., Lemaire, F. and Brun-Buisson, C. (1997) Lower Respiratory Tract Colonization and Infection during Severe Acute Respiratory Distress Syndrome: Incidence and Diagnosis. American Journal of Respiratory and Critical Care Medicine, 156, 1092-1098. http://dx.doi.org/10.1164/ajrccm.156.4.9701065

[15] Garnacho Montero, J., Garcia-Garmendia, J.L., Barrero-Almodovar, A., Jimenez-Jimenez, F.J., Perez-PAredes, C. and Ortiz-Leyba, C. (2003) Impact of Adeguate Empirical Antibiotic Therapy on the Outcome of Patients Admitted to the Intensive Care Unit with Sepsis. Critical Care Medicine, 31, 2742-2751. http://dx.doi.org/10.1097/01.CCM.0000098031.24329.10

[16] Iregui, M., Ward, S., Sherman, G., Fraser, V.J. and Kollef, M.H. (2002) Clinical Importance of Delays in the Initiation of Appropriate Antibiotic Treatment for Ventilator-Associated Pneumonia. Chest, 122, 262-268. http://dx.doi.org/10.1378/chest.122.1.262

[17] Luna, C.M., Blanzaco, D., Niederman, M.S., Matarucco, W., Baredes, N.C., Desmery, P., Palizas, F., Menga, G., Rios, F. and Apezteguia, C. (2003) Resolution of Ventilator-Associated Pneumonia: Prospective Evaluation of the Clinical Pulmonary Infection Score as an Early Clinical Predictor of Outcome. Critical Care Medicine, 31, 676-682. http://dx.doi.org/10.1097/01.CCM.0000055380.86458.1E 
Scientific Research Publishing (SCIRP) is one of the largest Open Access journal publishers. It is currently publishing more than 200 open access, online, peer-reviewed journals covering a wide range of academic disciplines. SCIRP serves the worldwide academic communities and contributes to the progress and application of science with its publication.

Other selected journals from SCIRP are listed as below. Submit your manuscript to us via either submit@scirp.org or Online Submission Portal.
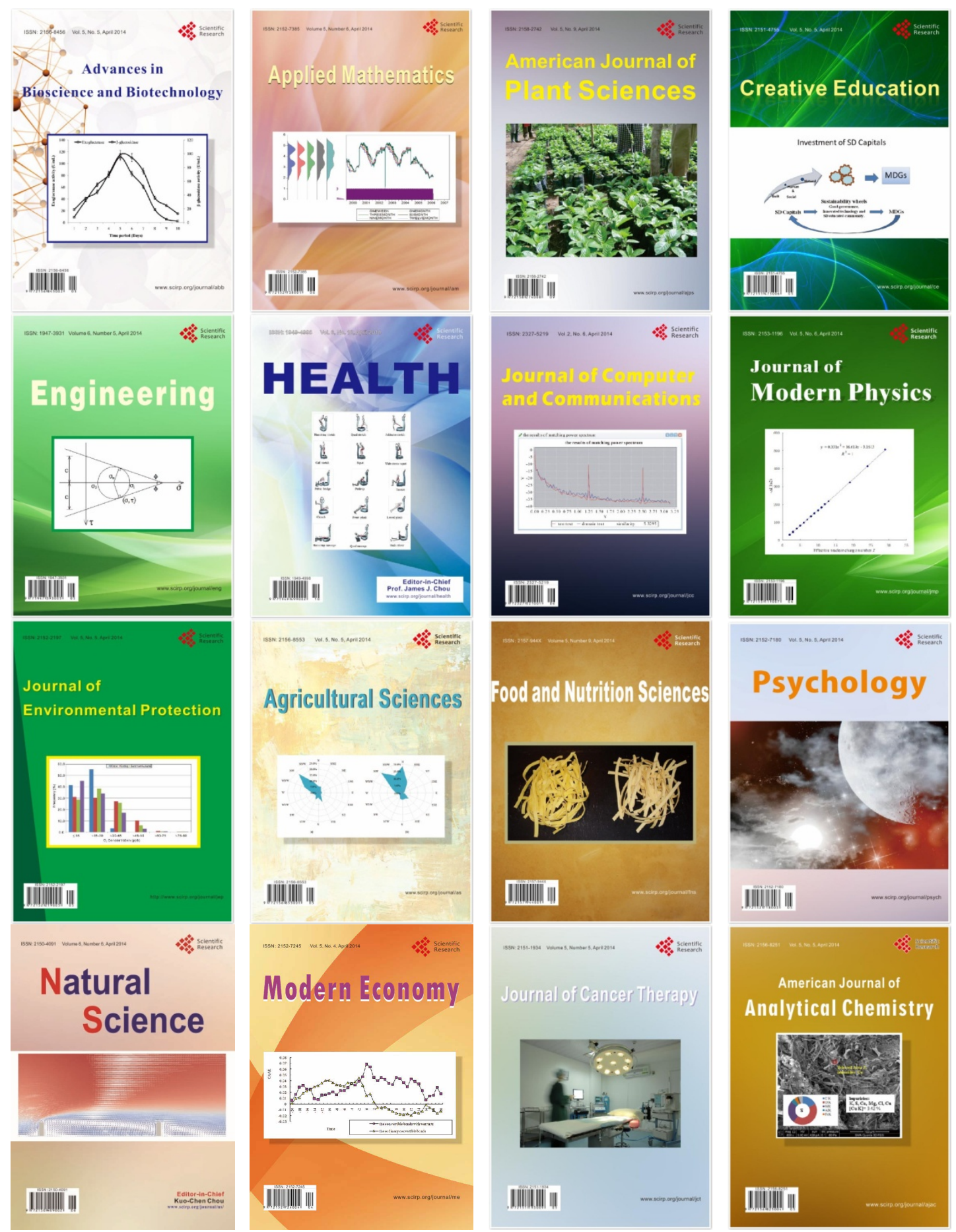